\title{
LA RELACIÓN ENTRE NEOINSTITUCIONALISMO ECONÓMICO Y SOCIOLÓGICO
}

Sagar Hernández Chuliá*

$\mathrm{E}$ 1 principal objetivo de este trabajo es demostrar la concordancia fundamental entre las aportaciones teóricas de los economistas y los sociólogos adscritos a la escuela neoinstitucionalista. La comparación se lleva a cabo agrupándolas en seis categorías. Las tres primeras (teleología, epistemología y metodología) proceden de la clásica taxonomía habermasiana relativa a la relación existente entre tipos de interés y de conocimiento (Habermas, 1997) ${ }^{1}$ y nos permiten cotejar cualesquiera disciplinas científicas; mientras que las tres últimas (agente individual, organizaciones e instituciones) aluden a tres conceptos teóricos que, además de encontrarse presentes en economía y sociología, resultan de una indudable importancia a la hora de caracterizar adecuadamente esta escuela.

No obstante, si pretendemos comparar las contribuciones teóricas sustantivas defendidas por economistas y sociólogos neoinstitucionalistas, debemos comenzar por precisar a qué nos referimos con dicho término. En este sentido, aunque no existe una definición de consenso, coincidimos con Caballero y Soto $(2013,133)$ en caracterizar esta corriente de pensamiento por la voluntad de sus seguidores de

\footnotetext{
* Doctor en Sociología, Universidad Complutense de Madrid, Madrid, España, [sagarhch@gmail.com]. Este artículo es una adaptación del epígrafe 5.3 "Relación entre el neoinstitucionalismo en economía y en sociología" de mi tesis doctoral "Principales puntos de convergencia entre las escuelas hegemónicas de teoría económica y sociológica desde la Ilustración escocesa hasta nuestros días". Agradezco las sugerencias de un evaluador anónimo. Fecha de recepción: 23-02-2016, fecha de modificación: 27-06-2016, fecha de aceptación: 20-10-2016. Sugerencia de citación: Hernández Ch., S. "La relación entre neoinstitucionalismo económico y sociológico", Revista de Economía Institucional 18, 35, 2016, pp. 123-149. DoI: http://dx.doi.org/10.18601/01245996.v18n35.07

${ }^{1}$ Taxonomía que, aunque el propio Habermas considere superada por su teoría de la acción comunicativa, y pese a que no fue elaborada con este propósito, resulta de gran utilidad a la hora de desarrollar este tipo de investigaciones.
} 
integrar el "modelo de elección individual en la tradición del análisis institucional comparado de la sociología, contextualizando institucionalmente la elección individual”.

Por otra parte, debemos tener muy presente que el neoinstitucionalismo no constituye un cuerpo de pensamiento uniforme. Así, pese a que la delimitación de programas de trabajo nunca pueda considerarse como definitiva, es posible identificar tres corrientes principales ${ }^{2}$. En primer lugar, nos encontramos con los autores adscritos a la nueva economía institucional (Coase, Williamson y North). Estos defienden que "lo que el economista estudia [o, al menos, ellos] es el funcionamiento de las instituciones sociales" (Coase, 1978, 206-207); eso sí, valiéndose de "la teoría económica estándar" (Coase, 1984, 230). En segundo lugar, la nueva sociología económica institucional de Victor Nee desarrolla "su análisis sociológico a partir del marco de la nueva economía institucional" (Caballero y Soto, 2013, 147). Finalmente, el neoinstitucionalismo del análisis organizativo de Paul DiMaggio y Walter Powell se decanta por analizar la influencia del "marco institucional y las creencias culturales [...] en el comportamiento de las organizaciones"(Caballero y Soto, 2013,144). En este escrito comparamos los aportes procedentes de los economistas adscritos a la nueva economía institucional y del nuevo institucionalismo sociológico, tanto en su vertiente de la nueva sociología económica institucional como en la del neoinstitucionalismo del análisis organizativo.

La relación que mantienen estos tres grupos de autores gira en torno a una explícita influencia mutua. Así, en economía, por ejemplo, podemos referirnos al esquema de cuatro niveles de análisis social que propone Williamson $(2000,596-600)$ y a cómo el autor introduce en este referencias a los trabajos desarrollados por Victor Nee o Paul DiMaggio. Por otro lado, desde la sociología, DiMaggio y Powell $(1999,36)$ subrayan que "la tradición analítica que inició Coase y reforzó Williamson ha sido retomada por historiadores de la economía, estudiantes de leyes y economía, teóricos de juegos y

\footnotetext{
2 En lo que sigue, además de referirnos a la nueva economía institucional, nos valemos de la taxonomía establecida por Caballero y Soto (2013) respecto al nuevo institucionalismo en sociología. Sin embargo, nos separamos de ella en dos puntos. Por una parte, no atendemos a la escuela denominada "nueva sociología económica" por considerar que los trabajos de estos autores, particularmente Mark Granovetter y Harrison White, se encuentran más próximos al enfoque de redes que a la doctrina neoinstitucionalista propiamente dicha. Por otra, tampoco incluimos referencias al "institucionalismo sociológico del desarrollo" defendido por Alejandro Portes y Lori Smith por considerar que aún no ha pasado el tiempo suficiente como para poder valorar en su justa medida sus aportaciones teóricas y si estas se han constituido realmente como una nueva corriente dentro de estas escuela.
} 
economistas organizacionales". También desde la sociología, Nee $(2005,49)$ vincula ambos campos al destacar cómo, por una parte, "los escritos de Ronald Coase, Douglass North y Oliver Williamson sobre la aparición y evolución de las instituciones económicas han inspirado un movimiento de amplia base en economía"; mientras que, por otra, "en sociología, los neoinstitutionalistas han reorientado el estudio de las organizaciones estudiando cómo el ambiente institucional y las creencias culturales dan forma a su comportamiento" (ibíd.).

\section{TELEOLOGÍA}

Para demostrar nuestra hipótesis principal partimos de la afirmación de que estos autores otorgan prioridad a un cierto tipo de interés cognoscitivo. Según Habermas $(1997,42)$, "la ciencia tiende a engañarse a sí misma acerca de intereses fundamentales, a los que no solo debe su fuerza impulsora, sino las propias condiciones de la objetividad posible". Así, podemos identificar tres tipos de acciones básicas: trabajo, lenguaje e interacción social; a cada una de las cuales le corresponde un tipo de interés: técnico, práctico de comprensión y emancipatorio. Nosotros consideramos que estas son las tres posibles formas que, efectivamente, puede presentar nuestra primera categoría, la teleológica. Sin embargo, Habermas añade que cada una de ellas alude a un cierto tipo de ciencia (empírico-analítica, histórico-hermenéutica o crítica), mientras que nosotros defendemos que pueden presentarse en cualquier disciplina científica; incluidas, claro está, la economía y la sociología. Por tanto, nuestro propósito en esta sección debe limitarse, como acabamos de comentar, a señalar la prioridad que cada uno de estos autores atribuye a un determinado tipo de interés cognoscitivo.

$\mathrm{Si}$ atendemos a los motivos que la academia sueca adujo en 1991 para otorgar a Coase el premio Nobel de economía, constatamos que esta se inclina a destacar su descubrimiento del papel que juegan los costos de transacción y los derechos de propiedad en la estructura institucional y en el funcionamiento de la economía en general. En este sentido, Coase defiende explícitamente que "lo que el economista estudia es el funcionamiento de las instituciones sociales que mantienen unido el sistema económico" (1978, 206-207). Pero añade:

Lo que distingue a los economistas institucionales modernos no es que hablen de las instituciones sino que utilicen la teoría económica estándar para analizar el funcionamiento de dichas instituciones y para descubrir qué lugar ocupan en el funcionamiento de la economía (Coase, 1984, 230).

Dos años después, con motivo de la concesión de este mismo galardón, el jurado subrayó la capacidad de North para renovar la investigación 
en historia económica aplicando teorías y métodos novedosos en la explicación de cambios económicos e institucionales. En un texto posterior, este mismo autor señaló que el objetivo de sus investigaciones "no es solo arrojar nueva luz sobre el pasado económico, sino también contribuir a la teoría económica proporcionando un marco analítico que nos permita comprender el cambio económico" (1994, 359). Finalmente, en 2009, el comité resaltó los aportes teóricos de Williamson al análisis del papel que juegan las empresas en los procesos de resolución de conflictos y sobre su función como estructuras de gobierno alternativas. A este respecto, el premiado había sostenido en una investigación previa que "el propósito de la ciencia no es la predicción, sino el conocimiento en sí mismo” (Williamson, 1989, 138). Como podemos comprobar, estos tres economistas otorgan prioridad al interés práctico de comprensión frente a otros tipos de interés cognoscitivo.

Por su parte, desde la sociología, Victor Nee $(2005,49)$ define su propia obra como un intento de "abogar por un nuevo enfoque para explicar cómo interactúan las instituciones con las redes sociales y las normas para dar forma y dirigir la acción económica"; mientras que el trabajo más destacado de DiMaggio y Powell (1983) pretende dar cuenta de los mecanismos que operan en el complejo proceso de isomorfismo institucional. Como resulta patente, también desde la sociología, se opta por priorizar el interés práctico de comprensión.

\section{EPISTEMOLOGÍA}

Nuestra categoría epistemológica alude al concepto de reglas lógicometódicas. Como en la anterior, también aquí identificamos tres tipos principales. Por un lado, las reglas hipotético-deductivas. Provienen del interés técnico y "permiten deducir hipótesis legiformes dotadas de contenido empírico [...] pueden interpretarse como enunciados acerca de la covarianza de magnitudes observables" (Habermas, 1997, 39). Por otro, en las reglas histórico-hermenéuticas, nacidas del interés práctico de comprensión, "es la comprensión del sentido y no la observación, lo que nos permite acceder a los hechos" (ibíd., 40). Por último, el interés emancipatorio emplea la autorreflexión de modo tal que "libera al sujeto de su dependencia de poderes hipostasiados" (ibíd., 41). No obstante, aunque aceptamos a efectos estrictamente heurísticos esta taxonomía, defendemos, y aquí nos distanciamos parcialmente de la doctrina original de Habermas, que estas tres formas pueden combinarse para dar lugar a configuraciones híbridas. 
Acabamos de mostrar la prioridad que los autores citados en el apartado anterior dan al interés práctico de comprensión. Según el modelo original de Habermas, a este le corresponde el desarrollo de reglas histórico-hermenéuticas. Pero, ¿es realmente así? No. En su lugar, y debido a su tendencia a introducir supuestos realistas en los modelos, elaboran una forma híbrida de reglas hipotético-deductivas e histórico-hermenéuticas que presentan seis características principales.

1. Establecen una clara distinción entre consideraciones lógicas y factuales. Así, Coase señala: "un teórico inspirado puede investigar sin trabajo empírico, pero en mi opinión es más probable que la inspiración llegue a través del impulso que proporciona una recopilación de datos sistemática" (1972, 71). En esta misma línea, Williamson argumenta que "el esfuerzo para poner en práctica las ideas prometedoras tiene dos partes: una teórica y otra empírica" $(2000,604)$ y defiende una estrategia consistente en confrontar el marco teórico con la evidencia empírica. Finalmente, North sostiene:

Las actuales investigaciones, que incluyen nuevas hipótesis que se enfrentan con la evidencia histórica, no solo crean un marco analítico que nos permite entender el cambio económico a través del tiempo (en un proceso que enriquece la teoría económica), sino que también permiten hacer frente eficazmente a una amplia gama de temas de actualidad (1994, 367).

Esta dicotomía entre consideraciones lógicas y factuales también es el punto de partida de los sociólogos neoinstitucionalistas. Así, Nee (1998a, 5) divide sus investigaciones en dos fases: en primer lugar, introduce proposiciones lógicas explícitas; y, posteriormente, las confronta con casos reales. Un ejemplo es la investigación que lleva a cabo junto con Ingram sobre el concepto de embeddedness (Nee e Ingram, 1998) y cómo lo ilustran atendiendo al funcionamiento efectivo del Cleo (Cornell's Large Experimental Organization). Es más, el propio Nee, en referencia explícita a los trabajos desarrollados por los economistas de esta escuela, pone de manifiesto cómo, aunque hayan hecho avances sustanciales en el campo de la investigación teórica gracias a la introducción del término de costo de transacción, "aún deben medir este concepto de un modo que sea útil para el análisis empírico" $(2005,63)$. En una línea muy similar se pronuncian también DiMaggio y Powell al afirmar que "la discusión teórica es susceptible de prueba empírica, y, así, de sentar ciertas proposiciones comprobables que pueden guiar análisis futuros" $(1983,156)$.

2. Dichos autores integran estos dos niveles de análisis elaborando modelos teóricos abstractos en forma de sistemas que incluyen supuestos realistas. Para Coase, el objeto de estudio de los economistas es "el sistema económico" $(1978,206)$. Según él, una de las principales 
razones de su éxito en otras ciencias sociales remite, precisamente, a su capacidad para estudiar "el sistema económico como un sistema unificado interdependiente" (ibíd., 209). Además, aboga por aplicar dicha concepción sistémica al análisis de las empresas (Coase, 1937, 393), permitiendo así al investigador dotarse de una definición de las mismas que resulte tan operativa como realista (ibíd., 386). De hecho, critica a la corriente teórica principal por "haberse vuelto cada vez más abstracta y por preocuparse poco por lo que sucede en el mundo real" $(1998,72)$. En este sentido, por ejemplo, su clásico trabajo sobre el costo social, aunque basado en un primer momento en una perspectiva teórica no realista, pronto incorpora postulados complementarios tomados del mundo real, como la existencia de costos de transacción $(1960,15)$.

Por otra parte, North entiende su propia obra como una modificación de la teoría económica convencional, mediante la introducción, con fines realistas, del supuesto de racionalidad imperfecta de los agentes y del factor tiempo:

El marco analítico es una modificación de la teoría neoclásica. Lo que retiene es el supuesto fundamental de la escasez [...] Lo que modifica es el supuesto de racionalidad. Lo que añade es la dimensión del tiempo (North, 1994, 359).

No obstante, y aunque sostiene que "el modelo es siempre un reflejo imperfecto de cómo funciona la economía de verdad" (North, 2008, 25), se inclina por analizarla desde una perspectiva sistémica, pues "la forma en que un sistema económico se organiza determina la distribución de los beneficios" (North, 1992, 6).

Pero, sin duda, el ejemplo más patente de convergencia teórica entre economistas y sociólogos neoinstitucionalistas en el ámbito epistemológico remite al esquema que presenta Nee $(2005,60)$ en la segunda edición de The handbook of economic sociology para analizar "el reto clave de la nueva sociología económica institucional”. Este último consiste en "especificar y explicar la naturaleza de las relaciones entre los elementos a diferentes niveles del modelo causal multinivel para explicar cómo las organizaciones sociales informales interactúan con las grandes estructuras institucionales" (ibíd.). A tal fin elabora un modelo basado en un trabajo previo de Williamson (1994).

Un antecedente de dicho modelo, que también "adapta la síntesis de Williamson de la economía neoinstitucional", podemos encontrarlo en la investigación que desarrollan Nee e Ingram sobre el concepto de embeddedness $(1998,31)$.

$\mathrm{Si}$ atendemos al modelo original que propone Williamson en la primera edición de The handbook of economic sociology, podemos 
comprobar que este autor pone en relación los tres mismos niveles de análisis: "el individuo, las estructuras de gobierno y el ambiente institucional” (1994, 80). En esta propuesta seminal, se centra en el segundo nivel y diferencia entre efectos principales y de retroalimentación. Los primeros se refieren a la influencia del entorno institucional en las estructuras de gobierno (modificando los parámetros) y de los individuos sobre estas últimas (atributos conductuales); los segundos muestran el efecto de dichas estructuras de gobierno sobre el entorno institucional (mediante acciones estratégicas) y sobre los individuos (modificando sus preferencias endógenas; un mecanismo por medio del cual también se hace sentir la influencia institucional).

Nee e Ingram (1998) introducen cuatro modificaciones a este modelo: 1) separan las instituciones formales de las no formales, $y$ localizan estas últimas en el campo de la interacción individual; 2) especifican los dos mecanismos mediante los cuales las normas afectan el comportamiento individual: incentivos y preferencias endógenas; 3) incluyen el funcionamiento de los pequeños grupos en el análisis de la acción individual, y 4) identifican el concepto de gobernanza de Williamson con el de organizaciones.

Por su parte, el modelo que propone Nee en solitario introduce tres cambios adicionales: 1) extrae de nuevo las normas informales del campo de la interacción individual y de los grupos; 2) identifica los cambios de parámetros con los mecanismos de mercado y con la regulación estatal, y 3) en el segundo nivel, diferencia entre organizaciones (que incluyen empresas y entidades sin ánimo de lucro) y mercado de producción (espacio reservado al análisis del campo organizacional).

Como resulta patente, estos tres modelos presentan un perfil sistémico donde los distintos elementos mantienen entre sí relaciones de mutua dependencia. Sin embargo, los esquemas de Nee y de Nee e Ingram amplían el foco con respecto al de Williamson pues incluyen también las relaciones entre los distintos niveles de análisis y, con ello, los mecanismos causales que operan del nivel micro al macro, y viceversa. Además, introducen supuestos realistas que permiten aplicar el modelo a una organización realmente existente como el cLEO.

En este sentido, aunque DiMaggio y Powell $(1999,36)$ también elaboran modelos teóricos abstractos en forma de sistemas y sostienen que "la nueva economía institucional añade una saludable dosis de realismo a los supuestos usuales de la teoría microeconómica", no muestran una proximidad formal tan acusada a la doctrina de los economistas de esta escuela como Nee. 
3. La introducción de supuestos realistas en los modelos permite a estos autores entender mejor cómo actúan los agentes en el mercado (economistas) o en la sociedad (sociólogos). En este sentido, desde la economía, Williamson afirma que "una primera lección de la teoría de la organización es la de describir los actores humanos en términos más realistas" (2002, 173); mientras que, desde la sociología, Nee critica los postulados poco realistas de la economía neoclásica, que consideran superfluos factores tan relevantes como "las instituciones, las relaciones sociales y las creencias culturales" (2005, 63). En este mismo orden de cosas, Powell argumenta que "los modelos estilizados de mercados, jerarquías y redes no describen perfectamente la realidad económica, pero permiten avanzar en la comprensión de la extraordinaria diversidad de acuerdos económicos que hoy existen en el mundo industrial" (1990, 301).

4. Si bien es cierto que la adopción de supuestos realistas ayuda a estos autores a entender mejor los fenómenos económicos y sociales, también supone una restricción en el empleo de la cláusula ceteris paribus, y los distancia de la doctrina que atribuye a dichos sistemas una tendencia general hacia el equilibrio. Dicha cláusula se introduce en contadas ocasiones y con el único propósito de elaborar un primer modelo teórico de carácter tentativo en la esfera lógica. En este sentido deben comprenderse las escasas menciones que encontramos en la obra de Coase (1937, 396), Williamson (1979, 240-241; 1981, 574; $2002,181)$ y North $(1992,11)$ en economía, o el hecho de que solo hayamos encontrado una en el texto de DiMaggio y Powell (1983, 154) en sociología.

Por otra parte, la noción de una tendencia general hacia el equilibrio, que solo se menciona tangencialmente en sociología, es usada con particular cautela por parte de los economistas de esta escuela. Así, aunque North señala la posible existencia de equilibrios múltiples que responderían a "las diferentes opciones que sigan agentes con gustos idénticos" (1993, 3), el único economista que introduce referencias explícitas, tanto a un equilibrio estático (basado en la experimentación constante que llevan a cabo los hombres de negocios), como a uno dinámico (al modificarse, con el tiempo, tanto los costos de organización dentro de la empresa como los costos de comercialización), es Coase (1937, 404-405).

En este sentido, desde la sociología, mientras que las principales figuras del neoinstitucionalismo del análisis organizativo parecen eludir el tema, Nee e Ingram advierten sobre cómo el tema de los equilibrios múltiples supone un difícil obstáculo para los teóricos a 
la hora de desarrollar una teoría de las normas. Argumentan, a este respecto, que Axelrod "empleó una simulación por ordenador para demostrar una variedad de 'juegos de normas' pero no pudo dar con una explicación desde la teoría de juegos para la emergencia y persistencia de dichas normas" (Nee e Ingram, 1998, 22). Como podemos comprobar, salvo en el caso de Coase, estos autores quedan lejos de afirmar inequívocamente una tendencia general de los sistemas hacia un único equilibrio más o menos estático.

5. Si nos fijamos en las metáforas que emplean estos autores para describir su trabajo, observamos cómo los sociólogos huyen de esta práctica mientras que las referencias de los economistas se dividen en dos grupos: por una parte, Coase $(1998,73)$ y North $(2008,21-22)$ aluden a la biología evolutiva; por otra, Williamson se refiere a la física, y considera los costos de transacción como "el equivalente económico de la fricción en los sistemas físicos” (Williamson, 1985, 19).

6. Todos estos autores se muestran partidarios de un esfuerzo multidisciplinario. A este respecto, quizá el ejemplo más notorio remita al hecho de que, por una parte, Williamson (1994) sea invitado a colaborar en un manual sobre sociología económica; por otra, que Nee y Swedberg (2008) hagan lo propio en uno sobre economía neoinstitucional. En cualquier caso, el papel que tanto economistas como sociólogos neoinstitucionales atribuyen a la teoría económica está lejos de poder calificarse como imperialismo economicista. Como recordamos, Coase considera que una de las razones del éxito de los economistas en otras ciencias sociales consiste en su capacidad para entender la economía como un sistema complejo. No obstante, según este mismo autor, dichas incursiones, lejos de responder al hecho de haber resuelto todos los problemas del sistema económico, ponen de manifiesto su búsqueda de "campos en los que puedan tener algún éxito" (Coase, 1978, 203). Además, sostiene:

La necesidad de tener en cuenta la influencia de otros sistemas sociales en el análisis del funcionamiento del sistema económico es ahora ampliamente aceptada por los economistas. Este tipo de trabajo se puede llevar a cabo en colaboración con otros científicos sociales, pero es poco probable que sea bien hecho sin economistas (ibíd., 201).

Del mismo modo, tanto North $(1994,362)$ como Williamson (2000, 600) califican de fundamentales las aportaciones que, desde la psicología y la ciencia cognitiva, se han venido realizando a la teoría de la decisión en economía. Este último incluso llega a afirmar que el análisis de los costos de transacción constituye "un enfoque interdisciplinario para el estudio de las organizaciones que aúna la economía, 
la teoría de la organización y ciertos aspectos de la Ley de contratos” (Williamson, 1981, 573).

Por su parte, Nee (1998a,1) expresa su total sintonía con los esfuerzos multidisciplinarios y argumenta que "el nuevo institucionalismo en sociología es parte de un paradigma emergente en las ciencias sociales. $\mathrm{E} 1$ interés en el nuevo paradigma institucional es impulsado por los avances en la investigación interdisciplinaria dirigidos a entender las instituciones". Además, señala que la "sociología tiene mucho que ganar con el nuevo interés en la producción de una teoría de las instituciones y el cambio institucional. Pero también tiene mucho que perder de no participar en este paradigma transdisciplinario" (ibíd., 2). En cualquier caso, en su trabajo con Ingram, también aclara que esta ciencia no corre el riesgo de caer bajo el influjo de la economía ya que "la economía neoinstitucionalista no es imperialista en la medida en que su proyecto consiste en elaborar una teoría de la vida económica basada en la 'elección-con-restricciones"' (Nee e Ingram, 1998, 40). Finalmente, DiMaggio y Powell (1999) sitúan explícitamente su programa de trabajo, el neoinstitucionalismo del análisis organizativo, entre las varias formas de institucionalismo contemporáneo y aprovechan para destacar su relación, tanto con las vertientes económicas como politológicas del mismo, al tiempo que subrayan sus vínculos con los estudios organizacionales propiamente dichos.

\section{METODOLOGÍA}

La tercera categoría a la que atendemos remite a la metodología. Según Habermas (1997), podemos identificar tres tipos: empírico-analítica, lógico-deductiva y dialéctica. Cada una de ellas proviene, respectivamente, de reglas hipotético-deductivas, histórico-hermenéuticas y auto-reflexivas. La primera aísla los elementos del fenómeno que se consideran pertinentes para analizarlos por separado. La segun$\mathrm{da}$ aplica principios generales preestablecidos a casos particulares mediante una cadena de razonamientos lógicos a fin de extraer una conclusión. La última enfatiza la concepción dinámica de la historia desde una perspectiva marxista. Nos valemos de estos tres tipos para comparar los aportes teóricos de los autores neoinstitucionalistas. Aunque, a diferencia de Habermas, contemplamos la posibilidad de formas intermedias.

Ya hemos señalado que estos autores adoptan una doctrina epistemológica híbrida de reglas hipotético-deductivas e históricohermenéuticas. A nivel metodológico, esta se traduce en una transposición de su dicotomía entre consideraciones lógicas y factuales. 
Así, comienzan estableciendo ciertos principios generales de los que deducen conclusiones mediante procedimientos lógicos (a la manera lógico-deductiva). Posteriormente, y con base en su experiencia (es decir, de manera empírico-analítica), derivan postulados subsidiarios. Luego los contrastan con la realidad. Es decir, coherentemente con su apuesta epistemológica, nos encontramos aquí ante una metodología híbrida de carácter secuencial.

En este sentido, Coase (1960), al analizar las externalidades, parte de una situación hipotética en la que "el negocio que daña debe pagar todo el daño causado y el sistema de precios funciona correctamente" (ibíd., 2). A continuación aporta un ejemplo matemático que simplifica su argumento e incluye una tabla de datos (ibíd., 3). Después presenta un escenario donde, "aunque se suponga que el sistema de precios funciona correctamente (o sea, sin costos), el negocio que ocasiona el daño no es responsable por él" (ibíd., 6). Es decir, establece un primer modelo teórico tentativo de carácter lógico que va haciéndose cada vez más complejo y donde las referencias matemáticas tienen un valor estrictamente heurístico. Finalmente, introduce cuatro ejemplos legales extraídos de la realidad para demostrar la operatividad de su modelo; y, de esta manera, incorpora la esfera factual a su razonamiento (ibíd., 8).

En los trabajos de Williamson se observa un modo de proceder muy similar. Por una parte, llama la atención sobre la posibilidad de que la traducción de las consideraciones lógicas al lenguaje matemático, aunque en ocasiones pueda resultar útil, implique "que los rasgos fundamentales de la teoría se queden fuera o resulten velados" (Williamson, 2000, 604-605). Por otra, aboga por hacer explícitos los "mecanismos mediante los cuales una teoría propuesta opera y las implicaciones refutables" (ibíd., 604); dando así entrada a la esfera factual en su argumentación.

Por otro lado, quizá los sociólogos neoinstitucionalistas que emplean más explícitamente las herramientas lógicas sean DiMaggio y Powell. En su famoso trabajo sobre el isomorfismo, comienzan identificando tres mecanismos: "1) isomorfismo coercitivo, que se deriva de la influencia política y del problema de la legitimidad; 2) isomorfismo mimético, resultante de las respuestas estándar a la incertidumbre, y 3) isomorfismo normativo, asociado a la profesionalización" (1983, 154). A continuación enuncian once predictores de dicho cambio en forma de hipótesis (ibíd., 154-156). Aunque no se detienen a comprobar su validez, afirman que deben ser empíricamente comprobados y con ello dan entrada a las consideraciones factuales. Esta misma 
forma de proceder es la que desarrollan Nee e Ingram (1998) en su artículo sobre la embeddedness. Establecen un modelo teórico que se va haciendo cada vez más complejo y que finalmente es contrastado con un ejemplo realmente existente: el CLEO.

\section{AGENTE INDIVIDUAL}

$\mathrm{E} 1$ análisis de los agentes individuales puede enfocarse de dos maneras: la formal, basada en la construcción de modelos pretendidamente no realistas, y la material, que atiende a su efectiva actuación en el mundo. Dado que estos autores abogan por contrastar sus hipótesis con la realidad, no sorprende que se inclinen por la segunda. Así, el análisis que a continuación presentamos se articula en torno a cinco características principales: su carácter realista y centrado en el interés propio, su concepción acotada de la racionalidad, la imposibilidad de que los agentes desarrollen comportamientos no racionales, el papel de la incertidumbre y de las expectativas, y la interacción social.

1. Con respecto a la primera característica, los economistas neoinstitucionalistas comienzan abogando por elaborar un modelo que dé cuenta del comportamiento real de los agentes. Como recuerda Williamson, "Coase sostiene que [...] la visión del hombre como maximizador racional de la utilidad [...] se debería abandonar" (1989, 138). Así, si consideramos al ser humano tal como es, inmediatamente identificamos dos rasgos principales: primero, su "racionalidad limitada" (ibíd.); segundo, que "es dado a perseguir su propio interés de un modo más profundo y problemático que su predecesor" (ibíd.). Pero, ¿en qué sentido resulta problemático este atender al interés propio? Según Williamson $(1981,574)$, la teoría de los costos de transacción, base de la economía neoinstitucional, "descansa en argumentos de economización”. Es decir, el análisis de los agentes individuales se apoya en una perspectiva maximizadora, pero no tanto de los resultados como de los procedimientos. En este sentido, dada la racionalidad limitada que se imputa a los agentes, su comportamiento debe ser considerado como satisfaciente. El elemento problemático de esta afirmación radica en nuestra capacidad para diferenciar en qué sentido, dado el postulado de racionalidad limitada de los agentes, su interés propio plasmado en conductas satisfacientes no oculta, en realidad, conductas maximizadoras encubiertas. En cualquier caso, debemos tener muy presente que, como también señala Coase, esta forma de proceder en pos del interés propio no se limita a la esfera económica. Un ejemplo remite al comportamiento de aquellos intelectuales que hacen compatible su apología de la no intervención estatal en el "mer- 
cado de las ideas" con la defensa de regulaciones gubernamentales en otros mercados (Coase, 1974, 386).

Desde la sociología, autores como Nee, Ingram o Powell también comparten esta perspectiva realista y basada en el interés propio de los agentes. Así, los dos primeros señalan que el supuesto neoclásico de información perfecta y capacidad cognitiva ilimitada resulta "patentemente falso' en condiciones de incertidumbre derivada del cambio institucional" $(1998,30)$ y recurren a "una definición "amplia" [del interés propio] según la cual los actores pueden valorar exclusivamente bienes sociales como el estatus o la reducción de la desaprobación social y el ostracismo" (ibíd., 30-31). En este mismo sentido, Powell señala que "economizar es un tema importante en muchas esferas [...] pero es uno de los muchos motivos teóricamente posibles de la acción, todos los cuales concuerdan con una comprensión amplia del concepto de interés propio" (1990, 323).

2. Con respecto a la concepción acotada de la racionalidad, Williamson, además de constatar cómo los agentes actúan con información imperfecta, subraya su "limitada competencia cognitiva" y alude a los costos de la toma de decisiones: "al ser la mente un recurso escaso, la especialización cognitiva presenta consecuencias a la hora de economizar" $(2000,600)$. Por otra parte, también destaca que, además, "los agentes económicos están autorizados a divulgar información de manera selectiva y distorsionada. Calcular esfuerzos para inducir a error, disfrazar, ofuscar y confundir son conductas admitidas"(Williamson, 1989, 139).

En esta misma línea, North señala que "las personas suelen actuar con información incompleta y con modelos subjetivamente derivados que con frecuencia son erróneos" (1994, 360); y que, "pese a que la investigación de la ciencia cognitiva revela que la mente es un 'instrumento' sumamente adaptable y creativo, sus poderes computacionales son muy limitados" $(1993,7)$. Además, diferencia el postulado de "racionalidad instrumental de la teoría neoclásica" $(1992,13)$ del de racionalidad procedimental, por el que él mismo se decanta. El primero implica que "los actores poseen la información necesaria para evaluar las alternativas de manera correcta y, en consecuencia, para tomar las decisiones que les permitan lograr los fines deseados" (ibíd.); mientras que en el segundo "no están totalmente informados, idean modelos subjetivos en forma de guías, y solo pueden corregir imperfectamente dichos modelos con base en la retroalimentación informativa" (ibíd.). North concluye afirmando que este último enfoque permite dar cuenta de "los mercados incompletos e imperfectos 
que caracterizan gran parte del presente [y] señala la clave de lo que hace que dichos mercados sean imperfectos, el costo de hacer transacciones" (ibíd.).

Esta concepción acotada de la racionalidad es plenamente compartida por los sociólogos de esta corriente. Así, por ejemplo, Nee e Ingram afirman:

Al desarrollar nuestro modelo, asumimos que los actores son racionales en cuanto toman decisiones de acuerdo con el criterio de costo-beneficio. Sin embargo, no los consideramos híper racionales [...] en posesión de una información perfecta y capacidad cognitiva ilimitada $(1998,30)$.

Habida cuenta de ello, según Nee (1998a, 1), los autores neoinstitucionalistas, entre los cuales él mismo se cuenta, deben partir de una "acción intencional de los individuos, aunque en condiciones de información incompleta, modelos mentales inadecuados y transacciones costosas". Desde ese enfoque los actores son "mejoradores más que maximizadores" (ibíd.). Una idea que comparten DiMaggio y Powell: "los individuos procuran maximizar su conducta hacia ordenamientos prioritarios estables y consistentes, pero lo hacen [...] en presencia de límites cognoscitivos, información incompleta y dificultades en el seguimiento y capacidad para hacer cumplir los acuerdos" $(1999,36)$.

3 . Estos autores también defienden que, del hecho de que los agentes presenten una racionalidad acotada, no se deriva necesariamente que desarrollen conductas no racionales. Así, desde la economía, Williamson afirma que "la ausencia de híper racionalidad no implica irracionalidad. Por el contrario, los agentes humanos a los que Simon alude pretenden actuar con eficacia. De esto es de lo que trata la racionalidad intencional" $(1981,571)$; mientras que desde la sociología, Nee e Ingram consideran que, si se parte de la definición más estricta de elección racional, "el problema reside en que es fácil encontrar ejemplos [de individuos] que no actúan racionalmente". Por lo que resulta "difícil creer que puedan ser tan racionales como supone el modelo más estricto de elección racional” (1998, 41, n. 4). Ahora bien, lejos de abandonar el criterio de racionalidad clásico, estos autores abogan por introducir "refinamientos en el modelo de elección racional básico [que] incrementen su aplicación a la sociología”(ibíd.).

4. El hecho de que estos autores imputen una racionalidad acotada a los agentes individuales da entrada a las nociones de incertidumbre y expectativas. A este respecto, Williamson, apoyándose en Koopmans (1957) y Knight (1947), atiende a tres tipos de incertidumbre: primaria, referente a la situación concreta; secundaria, derivada de la falta de comunicación entre quien toma las decisiones y los planes de otros; y 
terciaria, "que emerge en escenarios en los que se aúnan la contratación incompleta y los activos específicos" $(1989,144)$. De manera similar, North $(1992,9)$ sostiene que "en un mundo de incertidumbre, nadie conoce la solución correcta a los problemas que se le presentan"; y señala que dicha incertidumbre, en el sentido de Knight, "persiste debido a que el 'paisaje humano' experimenta continuamente cambios inducidos, en parte por acciones no humanas, pero, especialmente, por los propios actores humanos" (North, 2008, 24). Estos escenarios, según Coase, son precisamente los que favorecen el surgimiento de expectativas pues "el hecho de que exista incertidumbre significa que la gente tiene que pronosticar las preferencias futuras" (1937, 400). Así, dichas preferencias son las que, como recuerda Williamson, "nos salvan de las peores consecuencias de los replicadores ciegos" (2000, 601).

5. Una cuestión íntimamente vinculada a la dicotomía que establece Knight (1947) entre "riesgo" (aleatoriedad con probabilidades conocidas) e "incertidumbre" (aleatoriedad con probabilidades desconocidas) es la interacción social. En este sentido, Williamson y North parten del hecho de que los resultados de la interacción humana no están sujetos a un riesgo ponderable. Esta situación hace que emerjan costos de transacción; es decir, "costos de especificar lo que se intercambia y de hacer cumplir los acuerdos consiguientes" (North, 1994, 361). Según Williamson, el análisis de tales costos parte de dos premisas: “1) el reconocimiento de que los agentes humanos están sujetos a una racionalidad limitada y 2) el supuesto de que, al menos algunos agentes, son dados al oportunismo" (1981,553), Además, dichos costos pueden ser de dos tipos: ex ante, "los costos de redacción, negociación y salvaguarda de un acuerdo" (Williamson, 1985, 21) y ex post:

1) Los costos en los que se incurre cuando las transacciones se separan de la "curva de contrato de cambio"; 2) los costos en los que se incurre si se producen regateos bilaterales para corregir los desajustes ex post; 3) los costos de constitución y funcionamiento asociados a las estructuras de gobierno, $[\mathrm{y}]$

4) los costos de establecer compromisos con seguridad (ibíd.).

De este modo, la primera premisa, la racionalidad acotada de los agentes, remite, a su vez, a problemas de información imperfecta, por ejemplo, en los contratos. A este respecto, Williamson afirma que, "teniendo en cuenta la racionalidad limitada, es imposible hacer frente a la complejidad en todos los aspectos contractuales pertinentes. Debido a ello, la contratación incompleta es lo mejor que se puede lograr" (1981, 553-554). En consecuencia, "todos los contratos posibles son incompletos” $(1989,139)$, y, por tanto, deben ser comprendidos como promesas, en el sentido de que los agentes no las cumplirán "si otros agentes se dan al oportunismo" (ibíd., 140). Además, dichos contratos 
incompletos "plantean problemas adicionales cuando se combinan con el oportunismo" (2000, 601). Por su parte, la segunda premisa, la actitud oportunista, presenta un tipo de agente que "prevé que el interés propio se busca con astucia" $(1981,554)$, frente al del modelo tradicional, que "se involucra en la simple búsqueda de su propio interés" (ibíd.). Así, el riesgo moral puede ser comprendido como "una forma particular de oportunismo" (ibíd., n. 9). Es precisamente en este tipo de escenarios en los que se hace más patente la importancia que cobran los lazos personales: "en el intercambio personal, los lazos de parentesco, la amistad, la lealtad personal y la repetición de tratos [limitan] el comportamiento de los participantes y reducen la necesidad de costos de especificación y ejecución" (North, 1992, 7-8).

Con respecto al cuarto y el quinto factor que definen esta caracterización de los agentes individuales por parte de los sociólogos de la corriente neoinstitucionalista, ya hemos señalado previamente cómo, según estos autores, la incertidumbre emerge en escenarios caracterizados por el cambio institucional. Sin embargo, no debemos perder de vista que esta es una característica propia de cualquier ámbito donde se produzcan interacciones humanas. Así, Nee argumenta que las "personas se benefician de la existencia de normas, pero estos beneficios se logran a costa del beneficio privado a corto plazo que podrían obtener los oportunistas" (1998a, 9). Dichos oportunistas son individuos "que persiguen ventajas privadas a costa de bienes colectivos” (ibíd.). Como podemos comprobar, el fenómeno al que aquí se alude es el del comportamiento gorrón y sus derivados: el riesgo moral y el problema principal-agente. Ahora bien, Nee también contempla el comportamiento contrario: el del zelote. Este se caracteriza por inducir un estado de conformidad excesiva que, aunque puede desembocar en situaciones sociales indeseadas, resulta en "una forma de cooperación necesaria a la hora de alcanzar bienes colectivos que, de otra manera, no podrían lograrse por individuos que persiguieran su propia ventaja privada" (ibíd.).

Como resulta patente, los aportes teóricos de los sociólogos mencionados en esta sección proceden, casi en su totalidad, de la nueva sociología económica institucional. Esta situación deriva del hecho de que los seguidores del neoinstitucionalismo del análisis organizativo establecen las organizaciones (y no los agentes individuales) como principal unidad de análisis. No obstante, esta misma razón es también la que explica que sean precisamente sus contribuciones las que adquieran un papel preponderante en la siguiente categoría. 


\section{ORGANIZACIONES}

Las organizaciones enfrentan dos tipos de restricciones: en la esfera interna han de lidiar con problemas asociados a la coordinación de las acciones individuales; en la externa, deben hacer operativa su acción colectiva. Así, para analizar la doctrina defendida por estos autores respecto a las organizaciones, debemos atender, por una parte, a su surgimiento y funciones; $y$, por otra, a las relaciones que estas mantienen entre sí.

1. Para los economistas neoinstitucionalistas, las organizaciones surgen como mecanismos de reducción de la incertidumbre en contextos caracterizados por la existencia de costos de transacción ligados tanto a la racionalidad limitada como a las actitudes oportunistas de los agentes. En este sentido, Coase afirma que "parece improbable que una empresa pudiera emerger sin la existencia de incertidumbre" (1937, 392). Así, su surgimiento responde, por una parte, a la existencia de costos relativos al descubrimiento de los precios en el mercado (racionalidad limitada); y, por otra, a los costos derivados de las negociaciones en transacciones múltiples (que pueden favorecer conductas oportunistas) (ibíd., 390-391). En esta misma línea, Williamson sostiene que el mundo de la "gobernanza" aparece porque:

La planificación es incompleta (a causa de la racionalidad limitada), las promesas pueden romperse (por oportunismo) y la identidad de las partes importa (debido a la especificidad de los activos). El imperativo de la organización que surge en tales circunstancias es el de organizar las transacciones para reducir la racionalidad limitada y, al mismo tiempo, protegerse contra el riesgo de oportunismo (Williamson, 1985, 32).

Los sociólogos neoinstitucionalistas, en particular los que se ocupan del análisis organizativo, coinciden con sus colegas economistas al señalar que la razón de ser de las organizaciones remite a su capacidad para reducir la incertidumbre. Así, DiMaggio y Powell aluden a "la importancia de la incertidumbre y su reducción mediante rutinas organizacionales" $(1999,56)$ y argumentan que los “campos organizacionales muy estructurados proporcionan un contexto en el que se logra que los esfuerzos individuales aborden racionalmente la incertidumbre" $(1983,147)$; una incertidumbre que, a su vez, remite a la "racionalidad limitada [...], poca definición o contestación de los fines [de la organización] [...] y tecnologías poco claras" (ibíd., 156).

Como podemos comprobar, todos estos autores asocian el surgimiento de las organizaciones a su capacidad para reducir la incertidumbre. No obstante, cabe preguntar, ¿solo existen dos alternativas en la esfera económica? Es decir, ¿solo pueden existir organizaciones (empresas) o mercados abiertos? Según Coase (1972, 64), así es. Sin 
embargo, Williamson exhibe, a este respecto, dos posturas claramente diferenciadas. La primera, heredera de la doctrina clásica de Coase, afirma la existencia de dos únicas formas: mercados y jerarquías (Williamson, 1975); la segunda da también entrada a configuraciones híbridas: "antes era de la opinión de que las transacciones intermedias eran muy difíciles de organizar y, por tanto, inestables [...] ahora estoy convencido de que las transacciones en ese rango intermedio son mucho más comunes" (Williamson, 1985, 83).

Desde la sociología, aunque se da entrada a las redes como mecanismo alternativo a los mercados y las jerarquías, se rechaza su consideración como punto intermedio, como un híbrido. Antes bien, según Powell, "el continuum mercado-jerarquía no hace justicia a la noción de forma reticular de organización” (1990, 295). Y añade: "No comparto la creencia de que la mayor parte de los intercambios comerciales puede situarse en uno de los polos del continuum mercados-jerarquías" (ibíd., 298).

Este continuum que establecen los seguidores de la nueva economía institucional implica la emergencia de diferentes tipos de gestión que, en última instancia, se traducen también en distintas modalidades, tanto de contratos como de mecanismos de incentivos y control. Así, en cuanto a los contratos, Williamson sostiene que el "derecho contractual clásico es congruente con, y apoya, la forma de organización de mercado autónomo" $(1991,271)$. Este se aplica a las transacciones económicas ideales "en las que la identidad de las partes es irrelevante" y es "interpretado de una forma muy legalista" (ibíd.). A su turno, "la forma del derecho contractual que soporta la jerarquía es la tolerancia" (ibíd.) basada en el consentimiento. Esta forma de actuar consiste en abstenerse de hacer algo a lo que uno tiene el derecho legal. En este sentido, su “organización interna es un modo aún más elástico y adaptable de obrar" (ibíd., 274). Finalmente, los modelos híbridos "se apoyan en el derecho contractual neoclásico" (ibíd., 271) que se articula en torno al "arbitraje y la doctrina de la excusa" (ibíd., 273) cuando no se puede ejecutar materialmente el deber contraído. En este tipo de contratos, las partes "mantienen la autonomía, pero son bilateralmente dependientes en un grado significativo” (ibíd., 271). Además, según este mismo autor, "los mercados y las jerarquías son polos opuestos" (ibíd., 280) también en lo que respecta a los mecanismos de incentivos y control. Así, Williamson establece el mercado y la jerarquía como dos formas límite y procede a definir los tipos híbridos como puntos intermedios: "En comparación con el mercado, sacrifican incentivos en favor de una mayor coordinación entre las partes. En comparación 
con la jerarquía, sacrifican la capacidad de cooperar en favor de una mayor intensidad de incentivos" (ibíd., 283).

Sin embargo, desde la sociología, Powell (1990) propone un análisis que atiende a tres formas diferenciadas de organización económica: mercados, jerarquías y redes; sin concebir a estas últimas como un punto intermedio. Es más, incluso sostiene que "solo en una minoría de casos puede decirse que la génesis de las formas reticulares de organización está orientada a minimizar los costos de transacción" (ibíd., 326). No obstante, también considera, y en este punto se aproxima a la doctrina defendida por Williamson, que cada una de estas formas se diferencia de las otras dos si atendemos tanto a su fundamento normativo como a los métodos de resolución de conflictos. Así, por una parte, en el mercado rigen los contratos y los derechos de propiedad, en las jerarquías las relaciones laborales y en las redes las fortalezas complementarias; mientras que, por otra, los métodos de resolución de conflictos a los que se recurre en los mercados son el regateo y los tribunales; en las jerarquías, la supervisión y la confianza administrativa; y en las redes, la reciprocidad y la reputación.

2. Ya dentro de la esfera interorganizativa, lo primero que debemos preguntarnos es cómo influyen, según los autores adscritos a la nueva economía institucional, los costos de transacción en los procesos de crecimiento e integración vertical de las compañías en tanto que organizaciones económicas. Coase empieza su famoso trabajo sobre La naturaleza de la empresa preguntándose por su razón de ser y diferenciando, en atención a la presencia o no de transacciones mercantiles, entre dos esferas: el mercado y la empresa. En el primero, "los movimientos de precios dirigen la producción y esta se coordina mediante una serie de transacciones de intercambio" (Coase, 1937, 388); en la segunda, "estas transacciones de mercado se eliminan y emerge un empresario coordinador que dirige la producción” (ibíd.). Pero si las empresas pueden suprimir los costos asociados a las transacciones de mercado, ¿por qué una sola empresa no realiza toda la producción? Porque las empresas no pueden expandirse indefinidamente. Existe un límite a partir del cual el costo de una transacción adicional dentro de una empresa iguala al costo de realizarla en el mercado, y comienzan a externalizarse las operaciones (ibíd., 395). Este límite establece un espacio potencial de crecimiento limitado por la emergencia de costos de transacción. Sin embargo, antes de llegar a ese punto existen mecanismos de crecimiento muy variados, entre los que se encuentran, según Coase, la combinación y la integración empresarial (ibíd., 397-398). Por su parte, Williamson sostiene que 
las relaciones entre empresas no se agotan en estos dos mecanismos. También pueden emerger redes empresariales ya que "no es suficiente asignar una transacción a una estructura de gobernanza (una empresa o un mercado). Además es necesario adaptar la relación de intercambio a las continuas necesidades de las partes" $(1981,570)$.

Desde la sociología, Powell (1990, 305-322) aporta algunos ejemplos de redes empresariales, como las de industrias artesanales, economías regionales y distritos industriales, alianzas estratégicas y asociaciones, o procesos de desagregación vertical. Sin embargo, y más allá de que Williamson -a diferencia de Powell- considere las redes como una forma intermedia entre el mercado y la empresa, quizá la cuestión más relevante a este respecto sean las distintas relaciones que, según este autor, pueden establecerse entre dichas empresas. Es en este sentido que debemos entender el concepto de isomorfismo, un término que alude al proceso mediante el cual "los actores racionales hacen a sus organizaciones cada vez más similares entre sí según intentan cambiarlas" (DiMaggio y Powell, 1983, 147). DiMaggio y Powell establecen dos tipos: competitivo e institucional, y señalan como el primero ha sido objeto de muy diversos estudios, mientras que el segundo, referente a la esfera política y ceremonial, apenas ha sido analizado. Se centran en este último e identifican tres mecanismos principales: 1) el isomorfismo coercitivo, que "resulta de presiones formales e informales que ejercen sobre las organizaciones otras organizaciones de las que dependen y de las expectativas culturales de la sociedad en la que operan" (ibíd., 150); 2) los procesos miméticos que surgen en escenarios de incertidumbre "cuando las tecnologías organizacionales son poco conocidas, las metas son ambiguas o el ambiente genera incertidumbre simbólica" (ibíd., 151), y 3) los procesos de profesionalización, es decir, "la lucha colectiva de los miembros de una profesión por definir las condiciones y métodos de trabajo, por controlar la producción de los productores, y por establecer una base cognitiva y la legitimación de su autonomía laboral” (ibíd., 152).

\section{INSTITUCIONES}

La última categoría de esta comparación remite a las instituciones, o "reglas constitutivas" (Searle, 1997, 45), es decir, pautas que "no solo regulan, sino que crean la posibilidad misma de ciertas actividades" (ibíd.). Apoyándonos en Hayek (1948), consideramos cuatro aspectos: 1) verificamos si se defiende una concepción natural que remita su génesis y lógica de funcionamiento a la condición humana; 2) atendemos a su carácter general, a nivel diacrónico, fijándonos en su 
evolución histórica, y a nivel sincrónico, comprobando si incluyen instituciones formales y no formales; 3 ) aludimos a su surgimiento espontáneo como producto no deliberado de la acción humana, y 4) examinamos las posibles relaciones conflictivas que pueden establecerse entre ellas, es decir, las contradicciones potenciales entre las funciones que se les atribuyen.

Los autores adscritos a la nueva economía institucional comienzan por destacar que el origen de las instituciones remite a la existencia de costos de transacción. En este sentido, por ejemplo, Williamson $(1985,17)$ dedica todo un libro a demostrar cómo "las instituciones económicas del capitalismo tienen la finalidad y el efecto de economizar costos de transacción”. No obstante, para presentar la doctrina defendida por estos autores preferimos centrarnos en los trabajos que, a este respecto, desarrolla Douglass North. Este autor también comienza atribuyendo su origen a la existencia de costos de transacción: "La información incompleta y la limitada capacidad mental para procesar la información determinan los costos de transacción que subyacen en la formación de las instituciones" $(1995,18)$. Y añade: "cuando los costos de transacción son significativos, las instituciones importan" $(1992,6)$. Es más, la razón de ser de las instituciones remite, según él, a su capacidad para "reducir la incertidumbre de las interacciones humanas" $(1993,7)$.

Pero, ¿qué entienden estos autores por instituciones? Según North, podemos comprenderlas como "limitaciones ideadas humanamente que estructuran la interacción humana" $(1994,360)$. Es decir, como "la estructura que los humanos imponen a sus relaciones con los demás" (1992, 9), como "mecanismo externos (a la mente) que los individuos crean para ordenar y estructurar el ambiente" (ibíd., 363). Por tanto, podemos comenzar afirmando que, para estos autores, las instituciones son, antes que nada, productos humanos.

Además, dichas instituciones pueden considerarse generales en tanto que, por un lado, están compuestas por "restricciones formales (p. ej., reglas, leyes, constituciones), informales (p. ej., normas de comportamiento, convenciones, códigos autoimpuestos de conducta) y sus formas de aplicación" (North, 1994, 360); y, por otro, se modifican con el tiempo en base al aprendizaje que adquieren los individuos y las organizaciones: "el aprendizaje de individuos y organizaciones es la mayor influencia en la evolución de las instituciones"(North, 1993, 3).

En este sentido, el propio North $(1993,1)$ enuncia cinco proposiciones sobre el cambio institucional: 1) su lógica de funcionamiento remite a la interacción entre instituciones y organizaciones en un 
entorno de escasez; 2) la competencia obliga a organizaciones e individuos a invertir continuamente en habilidades y conocimientos para sobrevivir. El tipo de habilidades y conocimientos de que disponen da forma a la percepción de las oportunidades y, por tanto, a sus elecciones; 3) el marco institucional proporciona los incentivos que determinan el tipo de habilidades y conocimientos que pueden producir más rentabilidad; 4) las percepciones de los agentes se derivan de sus construcciones mentales, y 5) las economías de escala, las complementariedades y las externalidades de red de una matriz institucional hacen que el cambio institucional se acelere y tome una determinada dirección. Así, dicho cambio institucional presenta un carácter incremental y dependiente de pautas. Incremental, "porque el cambio a gran escala perjudicaría a las organizaciones que ya existen y, por tanto, estas se oponen firmemente a él” (ibíd., 3); y dependiente de pautas porque la "dirección del cambio institucional gradual será consistente con la matriz institucional existente. Se regirá por el tipo de conocimientos y habilidades en los que han invertido los empresarios y miembros de las organizaciones" (ibíd.).

Por otro lado, los cambios institucionales presentan perfiles distintos si atendemos a las instituciones formales o no formales. Así, el cambio institucional de reglas no formales, a diferencia del caso de las formales, "se producirá de forma mucho más gradual, y en ocasiones de un modo bastante inconsciente" $(1992,11)$. Es decir, para North es posible que las instituciones informales se originen de manera espontánea. Ahora bien, dicho cambio institucional, se produzca en la esfera formal o no formal, no implica necesariamente un progreso evolutivo: "No hay ninguna implicación de progreso evolutivo o de crecimiento económico, solo de cambio" $(1993,2)$.

Además, las instituciones pueden presentar desajustes y, de este modo, entrar en conflicto. Así, un escenario caracterizado por la presencia de inconsistencias entre reglas formales y no formales puede resultar en "tensiones que suelen ser resueltas mediante una reestructuración de las limitaciones generales en ambas direcciones, que produce un nuevo equilibrio mucho menos revolucionario de lo que la retórica sugiere" $(1992,13)$.

Por su parte, desde la sociología, Nee también defiende que las "instituciones reducen la incertidumbre en las relaciones humanas" (1998a, 8). Estas presentan un carácter natural puesto que los individuos las producen con el fin de "captar las ganancias de la cooperación" (Nee e Ingram, 1998, 27), y pueden ser formales o informales. Las de carácter informal emergen de modo espontáneo en la interacción 
social, en forma de "contratos implícitos" (ibíd., 25) y "se basan en mecanismos informales de vigilancia" (ibíd., 19); mientras que las de carácter formal remiten a "reglas explícitas que se basan en mecanismos formales de vigilancia y cumplimiento" (ibíd., 25). En cualquier caso, "cuando las reglas formales e informales están estrechamente acopladas, se refuerzan mutuamente" (Nee, 1998b, 87). Aunque este autor no descarta la posibilidad de que se presenten desajustes. Entonces, las "normas informales evolucionan hacia "normas de oposición' que animan a los individuos a enfrentarse directamente con las reglas formales" (ibíd., 88), y dan lugar "al conflicto organizacional y a un faccionalismo que suelen resultar en una baja moral" (ibíd.). En este sentido, Nee advierte que una de las consecuencias previsibles de dicho escenario remite a un aumento de los costos de vigilancia (1998a, 9-10).

En esta misma línea se pronuncian DiMaggio y Powell. Para estos autores, las instituciones son naturales y conflictivas porque, respectivamente, son "producto de las acciones humanas"(DiMaggio y Powell, 1999, 68) y “se construyen mediante un proceso de conflicto y de prueba" (ibíd.). Por otro lado, también pueden ser consideradas generales por dos razones. En primer lugar, porque evolucionan históricamente en íntima relación con los mitos prevalecientes en el entorno cultural (DiMaggio, 1997); y a este respecto, DiMaggio defiende que "se puede considerar que nuestras nociones de empresa y mercado emanan de una explicación que ofrece la cultura occidental" $(1990,120)$. En segundo lugar, porque incluyen instituciones formales e informales. En este sentido, no debemos perder de vista que el proceso de institucionalización al que estos autores aluden remite, en última instancia, a un mecanismo por medio del cual los mitos racionales (informales) se establecen como modelos organizacionales legítimos (formales). Así, DiMaggio y Powell siguen la senda trazada por Meyer y Rowan (1977) al analizar cómo determinadas estructuras organizativas formales se ven forzadas a adoptar determinadas normas institucionales a fin de poder dotarse de recursos, estabilidad y legitimidad. Finalmente, para estos autores, las instituciones también tienen un origen espontáneo, como lo demuestra el hecho de que hagan alusión a cómo los "campos organizacionales altamente estructurados proporcionan un contexto en el que los esfuerzos individuales para tratar racionalmente con la incertidumbre y las restricciones a menudo conducen, en el agregado, a una homogeneidad en la estructura, la cultura y los productos" $(1983,147)$. Por cierto, esta referencia al papel que juegan los campos organizacionales altamente estructurados a la 
hora de reducir la incertidumbre no hace sino poner de manifiesto como estos autores coinciden con los economistas de esta escuela a la hora de comprender las instituciones como mecanismos orientados a reducir la incertidumbre.

\section{CONCLUSIONES}

A la vista de estos resultados podemos concluir que si bien todos los economistas y sociólogos adscritos a la corriente neoinstitucionalista priorizan el interés práctico de comprensión, también establecen una forma epistemológica híbrida de reglas hipotético-deductivas e histórico-hermenéuticas. Esta nueva configuración se traduce, a nivel metodológico, en una estrategia consistente en partir del establecimiento de unos principios generales de los cuales deducir conclusiones mediante procedimientos lógicos (de un modo lógico-deductivo); para después contrastar su validez atendiendo a la realidad (a la manera empírico-analítica).

Por otra parte, estos autores también parten de una caracterización de los agentes individuales de signo material que enfatiza su carácter realista y centrado en el interés propio, atiende a su racionalidad acotada, establece la imposibilidad de que desarrollen conductas no racionales, destaca el papel que juegan la incertidumbre y las expectativas, e incorpora las interacciones sociales. Además, remiten el surgimiento de las organizaciones a su capacidad para reducir la incertidumbre. Y finalmente, entienden las instituciones como fenómenos generales que emergen de la propia condición humana pero que, pese a ser resultado de las acciones de los individuos, no deben comprenderse necesariamente como productos intencionales. Del mismo modo, contemplan la posibilidad de que dichas instituciones entren en conflicto al presentar funciones contradictorias. En definitiva, esta investigación nos permite demostrar la concordancia fundamental existente entre las aportaciones teóricas procedentes de economistas y sociólogos adscritos a la corriente neoinstitucionalista.

No obstante, también pone de manifiesto dos discrepancias que abren la posibilidad a establecer un fructífero debate en el seno de esta escuela.

1. Dentro de la esfera sociológica, las aportaciones procedentes de la sociología económica institucional y del neoinstitucionalismo del análisis organizativo parten de establecer dos unidades de análisis distintas. Mientras que Paul DiMaggio y Walter Powell parten del estudio de las organizaciones, Nee otorga prioridad a los agentes individuales. Este hecho supone un desajuste del peso relativo que 
estos autores otorgan a sus respectivas aportaciones teóricas en ambas categorías. Pero, sobre todo, nos hace plantearnos en qué medida puede considerarse como neoinstitucionalista el análisis que llevan a cabo DiMaggio y Powell. No debemos perder de vista que el principal rasgo definitorio de esta escuela de pensamiento remite a su pretensión de integrar el modelo de elección individual en el marco más amplio del análisis institucional de raíz sociológica. En este sentido, Nee sostiene que "los argumentos centrales del nuevo institucionalismo organizativo no son inconsistentes con la racionalidad-limitada-al contexto si los actores son vistos como organizaciones" (1998a,11). Sin embargo, debemos plantearnos en qué medida resulta legítimo considerar a las organizaciones como actores y si la racionalidad organizacional es asimilable a la desarrollada por los agentes individuales.

2. En lo que respecta a la taxonomía mercados-redes-jerarquías, mientras que desde la nueva economía institucional Williamson incorpora las redes como formas intermedias entre mercados y jerarquías, Powell, desde el neoinstitucionalismo del análisis organizativo, aboga por comprenderlas como una forma específica con identidad propia; es decir, impugna su caracterización como forma intermedia e incluso parece sugerir su prioridad analítica frente a las otras dos. En este sentido podemos preguntarnos si ambas doctrinas son compatibles y, en caso de no serlo, qué taxonomía resulta más adecuada.

\section{REFERENCIAS BIBLIOGRÁFICAS}

1. Caballero, G. y D. Soto-O. "La nueva sociología económica y el nuevo institucionalismo en economía: enfoques contemporáneos”, $\mathrm{X}$. C. Arias y G. Caballero, eds., Nuevo institucionalismo: gobernanza, economía y politicas públicas, Madrid, cis, 2013, pp. 131-156.

2. Coase, R. H. "The nature of the firm", Economica 4, 16, 1937, pp. 386-405.

3. Coase, R. H. "The problem of social cost", The Journal of Law E Economics 3, 1960, pp. 1-44.

4. Coase, R. H. "Industrial organization: A proposal for research", V. R. Fuchs, ed., Economic research: Retrospect and prospect, vol. 3: Policy issues and research opportunities in industrial organization, Cambridge, Mass., NBER, 1972, pp. 59-73.

5. Coase, R. H. "The market for goods and the market for ideas", The American Economic Review 64, 2, 1974, pp. 384-391.

6. Coase, R. H. "Economics and contiguous disciplines", The Journal of Legal Studies 7, 2, 1978, pp. 201-211.

7. Coase, R. H. "The new institutional economics", Journal of Institutional and Theoretical Economics 140, 1984, pp. 229-231.

8. Coase, R. H. "The new institutional economics", American Economic Review 88, 2, 1998, pp. 2-74. 
9. DiMaggio, P. J. "Cultural aspects of economic action and organization”, R. O. Friedland, y A. F. Robertson, eds., Beyond the marketplace: Rethinking economy and society, Nueva York, Aldine, 1990, pp. 113-136.

10. DiMaggio, P. J. “Culture and cognition”, Annual Review of Sociology 23, 1997, pp. 263-287.

11. DiMaggio, P. J. y W. W. Powell. "The iron cage revisited: Institutional isomorphism and collective rationality in organizational fields", American Sociological Review 48, 2, 1983, pp. 147-160.

12. DiMaggio, P. J. y W. W. Powell. "Introducción”, P. J. DiMaggio y W. W. Powell, eds., El nuevo institucionalismo en el análisis organizacional, México DF, FCE, 1999, pp. 33-75.

13. Habermas, J. “Conocimiento e interés” [1968], M. Jiménez, ed., Jürgen Habermas, Conocimiento e interés. Edmund Husserl, La filosofía en la crisis de la humanidad europea, Valencia, Universitat de València, 1997, pp. 33-47.

14. Hayek, F. A. "Individualism: True and false" [1946], Individualism and economic order, Chicago, University of Chicago Press, 1948, pp. 1-32.

15. Knight, F. Riesgo, incertidumbre y beneficio [1921], Madrid, Aguilar, 1947.

16. Koopmans T. Three essays on the state of economic science, Nueva York, McGraw-Hill, 1957.

17. Meyer, J. y B. Rowan. "Institutionalized organizations: Formal structure as myth and ceremony”, American Journal of Sociology 83, 2, 1977, pp. 340-363.

18. Nee, V. y P. Ingram. "Embeddedness and beyond: Institutions, exchange, and social structure", M. Brinton y V. Nee, eds., The new institutionalism in sociology, Nueva York, Russell Sage Foundation, 1998, pp. 19-45.

19. Nee, V. y R. Swedberg. "Economic sociology and new institutional economics", C. Ménard y M. M. Shirley, eds., Handbook of new institutional economics, Dordrecht, Springer, 2008, pp. 789-818.

20. Nee, V. "Sources of the new institutionalism", M. Brinton y V. Nee, eds., The new institutionalism in sociology, Stanford, Stanford University Press, 1998a, pp. 1-16.

21. Nee, V. "Norms and networks in economic and organizational performance", American Economic Review 88, 2, 1998b, pp. 85-89.

22. Nee, V. "The new institutionalisms in economics and sociology" [1994], N. Smelser y R. Swedberg eds., The handbook of economic sociology, 2. ed., Princeton, Princeton University Press, 2005, pp. 49-74.

23. North, D. C. “Transaction costs, institutions, and economic performance”, San Francisco, International Center for Economic Growth, occasional papers 30, 1992, [http://khosachonline.ucoz.com/_ld/1/144_chi_ph_ gd-th_ch.pdf].

24. North, D. C. "Five propositions about institutional change", economics working paper archive, 1993, [http://ecsocman.hse.ru/ data/874/750/1216/9309001.pdf].

25. North, D. C. "Economic performance through time", American Economic Review 84, 3, 1994, pp. 359-368. 
26. North, D. C. "The new institutional economics and third world development", J. Harris et al., eds., The new institutional economics and third world development, Londres y Nueva York, Routledge, 1995, pp. 17-26.

27. North, D. C. "Institutions and the performance of economies over time”, M. M. Shirley y C. Ménard, eds., Handbook of new institutional economics, Heidelberg, Springer, 2008, pp. 21-30.

28. Powell, W. W. "Neither market nor hierarchy: Network forms of organization”, B. M. Staw y L. L. Cummings, eds., Research in organizational behavior, vol. 12, Greenwich, JAI Press, 1990, pp. 295-336.

29. Searle, J. R. La construcción de la realidad social [1995], Barcelona, Paidós, 1997.

30. Williamson, O. E. Markets and hierarchies: Analysis and antitrust implications, Nueva York, Free Press, 1975.

31. Williamson, O. E. "Transaction-cost economics: The governance of contractual relations", Journal of Law and Economics 22, 2, 1979, pp. 233-261.

32. Williamson, O. E. "The economics of organization: The transaction cost approach", American Journal of Sociology 87, 3, 1981, pp. 548-577.

33. Williamson, O. E. The economic institutions of capitalism. Firms, markets, relational contracting, Nueva York, Free Press, 1985.

34. Williamson, O. E. “Transaction cost economics”, R. Schmalensee y R. Willig, eds., Handbook of industrial organization, vol. I, Nueva York, North-Holland, 1989, pp. 135-182.

35. Williamson, O. E. "Comparative economic organization: The analysis of discrete structural alternatives", Administrative Science Quarterly 36, 2, 1991, pp. 269-296.

36. Williamson, O. E. "Transaction cost economics and organization theory", N. J. Smelser y R. Swedberg, eds., The handbook of economic sociology, Nueva York, Russell Sage Foundation, 1994, pp. 77-107.

37. Williamson, O. E. "The new institutional economics: Taking stock, looking ahead", Journal of Economic Literature 38, 3, 2000, pp. 595-613.

38. Williamson, O. E. "The theory of the firm as governance structure: From choice to contract", Journal of Economic Perspectives 16, 3, 2002, pp. 171-195. 